\title{
Incidence of Down Syndrome in Dubai, UAE
}

\author{
Sabita K. Murthy Ashok K. Malhotra Sara Mani Maryam Essa A. Shara \\ Eman Essa Mohd Al-Rowaished Sehba Naveed Abdulla Ibrahim AlKhayat \\ Mahmoud Taleb AIAli \\ Department of Genetics, AI Wasl Hospital, Department of Health and Medical Services, Dubai, UAE
}

\section{Key Words}

Down syndrome $\cdot$ Down syndrome, incidence $\cdot$

Maternal age $\cdot$ Ethnicity $\cdot$ Middle East

\begin{abstract}
Objective: To describe incidence of Down syndrome in Dubai, United Arab Emirates (UAE). Subjects and Methods: A total of 63,398 newborn babies in Dubai $(24,250$ UAE nationals and 39,148 non-UAE) during a 5 -year period of 19992003 were routinely examined by experienced nurses, neonatologists, pediatricians and/or general practitioners for symptoms of Down syndrome. Those suspected with Down syndrome were referred to the cytogenetic laboratory for karyotyping. Results: A total of 141 cases were confirmed cytogenetically as Down syndrome. Of these, 139 were trisomy 21 and of the remaining 2, 1 was a translocation and the other a mosaic. The overall incidence of Down syndrome in Dubai was $1 / 449$ live births (2.2 per 1,000); $1 / 319$ live births (3.13 per 1,000 ) among UAE nationals and $1 / 602$ live births (1.66 per 1,000) among non-UAE nationals. The mean maternal age of UAE national mothers was $33.48 \pm 8.08$, with $41.66 \%$ of the mothers being in the advanced maternal age group (>35 years). The higher incidence of Down syndrome
\end{abstract}

\section{KARGER}

Fax +41613061234

E-Mail karger@karger.ch

www.karger.com
(C) 2007 S. Karger AG, Basel

1011-7571/07/0161-0025\$23.50/0

Accessible online at:

www.karger.com/mpp among UAE nationals is comparable to incidences reported for other Arab populations in the Middle Eastern region. Advanced maternal age, with mothers bearing children until their 50s and higher parity, appear to be the major contributing factors for the increased incidence. Conclusion: The study indicates the need to provide efficient genetic counseling and to introduce an effective antenatal screening program and prenatal diagnostic services to reduce the psychological and genetic burden on the families and community.

Copyright $\odot 2007$ S. Karger AG, Basel

\section{Introduction}

Down syndrome is one of the major causes of mental retardation, and is thus of major socioeconomic concern. The overall incidence of Down syndrome worldwide is reported to be $1 / 600$ to $1 / 800$ live births [1]. There are several reports on the increased incidence of Down syndrome, from different parts of the world, with respect to ethnicity and maternal age [1-8], including some of the major cities/regions in the Middle East [9-19], but no such data is yet available for the large cosmopolitan city of Dubai, which is one of the major cities in the United 
Fig. 1. Incidence of Down syndrome (per 1,000 live births) among the UAE national and non-UAE national population of Dubai during the period of 1999-2003.

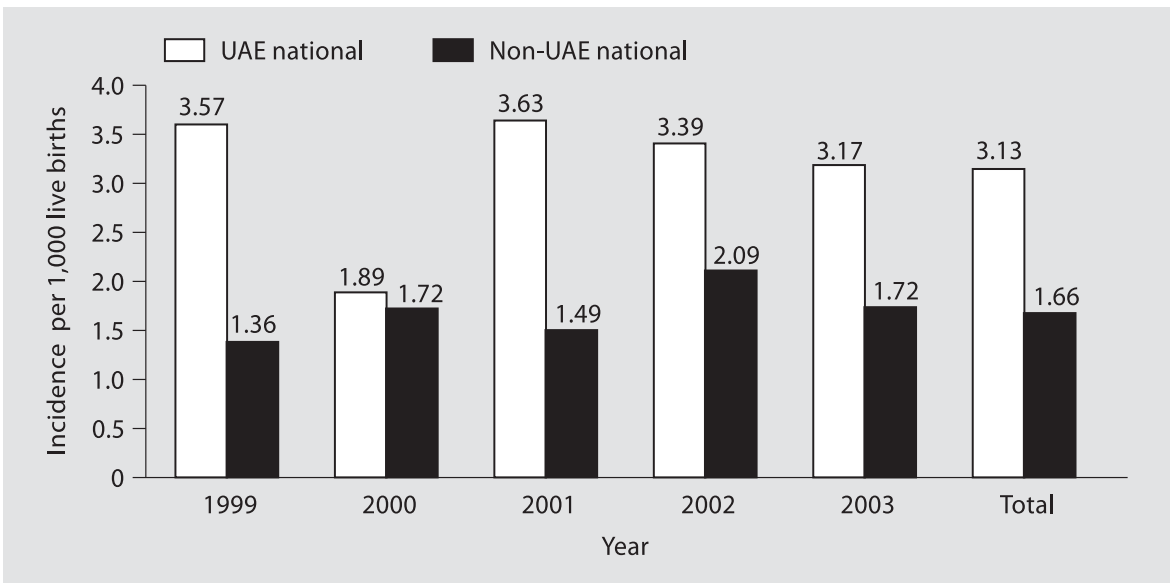

Table 1. Cytogenetically confirmed Down syndrome and their types during 1999-2003

\begin{tabular}{llll}
\hline & \multicolumn{2}{l}{ Number of cases } & \multirow{2}{*}{ Total } \\
\cline { 2 - 3 } & UAE & non-UAE & \\
\hline Trisomy 21 & & & \\
$\quad$ Male: $47, \mathrm{XY},+21$ & 39 & 31 & $49.64 \%$ \\
$\quad$ Female: $47, \mathrm{XX},+21$ & 36 & 32 & $48.22 \%$ \\
Translocation 21 & & & \\
$\quad$ 46,XY,t(14;21),+21 & 1 & 0 & $0.71 \%$ \\
Mosaic, 47,XY,+21/46,XY & 0 & 1 & $0.71 \%$ \\
Variant, 47,XX,+21,inv(9q) & 0 & 1 & $0.71 \%$ \\
Total Down syndrome & 76 & 65 & \\
Total live births & 24,250 & 39,148 & \\
Incidence & & & \\
$\quad$ DS/live births & $1 / 319$ & $1 / 602$ & \\
$\quad$ DS per 1,000 & 3.13 & 1.66 & \\
\hline
\end{tabular}

DS = Down syndrome. Range of age of Down syndrome at referral $=$ newborn to $3 \frac{1}{2}$ years.

Arab Emirates (UAE). We present here comprehensive data on Down syndrome for a period of 5 years (19992003) with special reference to the incidence, maternal age and parity among UAE nationals.

\section{Subjects and Methods}

The study group was taken from 63,398 newborn babies in Dubai, 24,250 born to UAE mothers and 39,148 born to non-UAE mothers during a period of 5 years, 1999-2003, as recorded in the annual statistics of the two major hospitals - Al Wasl and Dubai
Hospital. Maternal health care is available to all in this population, irrespective of ethnicity. After a routine examination of the newborns by experienced nurses, neonatologists, pediatricians and/or general practitioners, those suspected of having Down syndrome were referred to the cytogenetic laboratory, the only major laboratory in Dubai where most of the cytogenetic referrals are made, for karyotyping to obtain a confirmed diagnosis. The oldest referral was that of a child 3.5 years of age. G-banded metaphase preparations were made from peripheral blood lymphocyte cells by routine tissue culture technique followed by cytogenetic banding and staining methods [20].

\section{Results}

A total of 141 cases were confirmed cytogenetically as Down syndrome. The majority (139/141) were trisomy 21, and of the remaining 2, 1 was a translocation and the other was a mosaic Down syndrome (table 1). The overall incidence of Down syndrome in this population was $1 / 449$ live births $(2.2$ per 1,000$)$. With respect to ethnic distribution, the incidence was found to be $1 / 319$ live births (3.13 per 1,000$)$ among the UAE nationals and $1 / 602$ live births (1.66 per 1,000) among the non-UAE nationals (fig. 1). The mean maternal age of UAE mothers with a Down syndrome child was $33.48 \pm 8.08$ years (range 17-54), of which $41.66 \%$ were in the advanced age group ( $>35$ years); that of the non-UAE mothers was $33.84 \pm 5.81$ years (range $23-45$ ), of which $40.47 \%$ were in the advanced maternal age group (fig. 2). The number of children born to mothers with a Down syndrome child was in the range of 1-14, with mostly the last or second last child being the Down syndrome child. 
Fig. 2. Age distribution among the UAE and non-UAE mothers with a Down syndrome child.

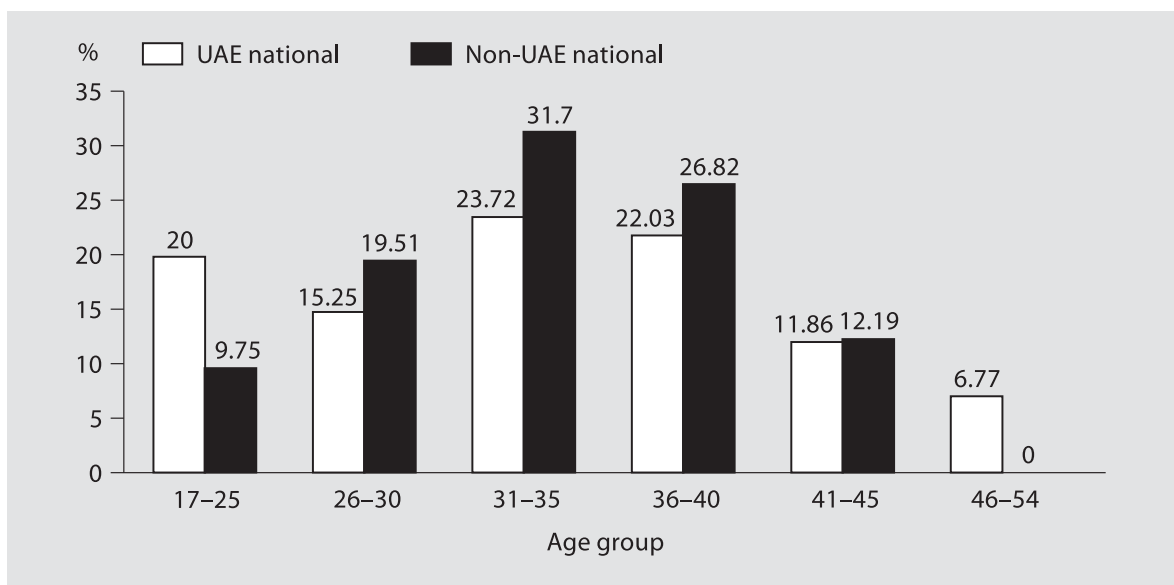

\section{Discussion}

The overall incidence of Down syndrome worldwide for all age groups is $1 / 800$ live births, and is shown to increase drastically to $1 / 400$ in older mothers, those above 35 years of age, to as high as $1 / 12$ by the age of 50 [1-4]. Though a definite cause leading to the increased risk of aneuploidy is not yet well understood, most of the reports suggest a strong relationship of Down syndrome with advanced maternal age [4-8]. Mothers under the age of 30 years who have had a previous child with Down syndrome or other aneuploid conception (trisomy 13, 18 or 21) have a higher risk, as high as 8 -fold of the age-related risk of trisomy 21, and a 1.6- to 1.8-fold increased risk for variable trisomies [5]. Effective antenatal screening programs and prenatal diagnostic services have been implemented in many countries for high-risk pregnancies including women above 35 years of age for early detection of such anomalies [2,3]. However, prenatal diagnosis is not yet in good practice in the majority of Arab counties. In Dubai, prenatal diagnosis by karyotyping was not available during the period of this report from 1999 to 2003, but has been offered recently, since 2005 .

The increased incidence of Down syndrome in Dubai is comparable to the reported incidences among Arab nationals from several other regions, namely Kuwait, Saudi Arabia, Qatar, Israel and Libya, which are in the range of 1.93-3.5/1,000 live births (table 2) [9-18]. The incidence of $3.13 / 1,000$ observed in the UAE population in Dubai is higher than most of the other Arab populations except for Kuwait, where it is reported to be between 2.9 and $3.50 / 1,000[9,10]$. The mean maternal age $(33.48 \pm 8.08$ years, range $17-54$ years) in UAE nationals was lower com-
Table 2. Incidence of Down syndrome as reported in other Arab populations

\begin{tabular}{lll}
\hline Country/city & $\begin{array}{l}\text { Incidence } \\
\text { (per 1,000) }\end{array}$ & Reference (first author) \\
\hline Kuwait & 3.50 & Farag, 1988 [9] \\
Kuwait & 2.90 & Al-Naggar, 1999 [10] \\
Libya & 1.93 & Verma, 1990 [11] \\
West Jerusalem & 2.40 & Harlap, 1974 [12] \\
Israel & 2.32 & Merrick, 2000 [13] \\
Negev Desert Bedouin & 2.90 & Abeliovich, 1986 [14] \\
Saudi Arabia & 1.80 & Niazi, 1995 [15] \\
Saudi Arabia & 2.34 & Amir, 2002 [16] \\
Qatar & 1.95 & Wahab, 2006 [17] \\
Dubai, UAE & 2.22 & Present study (all DS) \\
& 3.13 & Present study \\
& & (UAE nationals only) \\
\hline
\end{tabular}

pared to Egypt (38.2 years) and Qatar (35.4 \pm 6.5 years, range 21-51), but was slightly higher than that of Lebanon (32.19 years) [17-19]. The number of mothers in the advanced maternal age group ( $>35$ years) as seen in our study $(41.66 \%)$ is similar to Lebanon (41.5\%), but is less than that reported in Qatar (48.5\%). In the present study we also observed that $20 \%$ of the UAE mothers belonging to the younger age group of 17-25 years had a child with Down syndrome compared to $9.75 \%$ of the non-UAE nations (fig. 2) and $10.1 \%$ of the Qatari population [17], suggesting the presence of some possible predisposing factor. A higher parity ranging from 1 to 14 was observed in the UAE mothers with child-bearing until as late as the mid-50s, which could also possibly be responsible for the increased 
incidence. There are controversial reports on the parity and risk of Down syndrome, but several suggest an increased risk with increasing parity [21-25]. Schimmel et al. [23] in their report suggest $15 \%$ greater risk than from age-related factors alone. A subsequent report by Chan et al. [24] suggest that there is no increased risk with increased parity and gravidity after adjustment for age, while a recent report by Doria-Rose et al. [25] suggests a trend towards increasing risk of Down syndrome with increased parity in both younger and older mothers. Recurrence of aneuploidy is a very rare event. Krishna Murthy and Farag [26] reported two unrelated Kuwaiti families each having 3 siblings with trisomy 21 . They proposed that some genetic predisposition and/or gonadal mosaicism could be the underlying cause of recurrent aneuploidy in these parents, thus increasing the risk of recurrence of such pregnancies [26]. Such recurrent aneuploidy was not seen in our study; nevertheless, as mentioned above, the observation that there are more mothers in the younger age group would indicate a possible genetic predisposition in this population.
Due to the lack of availability of statistical information from the newborn registry on the year-wise maternal age of all the mothers, computation of a risk assessment for Down syndrome similar to that of Carothers et al. [27] was not possible.

\section{Conclusion}

The present study suggests that the increased incidence of Down syndrome in the UAE population is most likely related to advanced maternal age, increased parity and probably some genetic predisposition and/or gonadal mosaicism. These should be considered as important factors while counseling the parents and families at risk. To provide a better healthcare service, effective antenatal screening to detect the high-risk pregnancies and efficient prenatal diagnostic services for an early diagnosis need to be established in the region, keeping in mind the religious and cultural sentiments. This would greatly help in reducing the psychological and genetic burden of the affected families as well as of the community.

\section{References}

1 Gardner RJM, Sutherland GR: Chromosome Abnormalities and Genetic Counseling, ed 3. Oxford, Oxford University Press, 2004.

$\checkmark 2$ Hecht CA, Hook EB: Rates of Down syndrome at live birth by one-year maternal age intervals in studies with apparent close to complete ascertainment in populations of European origin: a proposed rate schedule for use in genetic and prenatal screening. Am J Med Genet 1996;62:376-385.

3 Hsu LYF: Prenatal diagnosis of chromosomal abnormalities through amniocentesis; in Milunsky A (ed): Genetic Disorders and the Fetus, ed 4. Baltimore, Johns Hopkins University Press, 1998, pp 179-248.

4 Hassold T, Chiu D: Maternal age-specific rates of numerical chromosome abnormalities with special reference to trisomy. Hum Genet 1985;70:11-17.

5 Warburton D, Dallaire L, Thangavelu M, Ross L, Levin B, Kline J: Trisomy recurrence: a reconsideration based on North American data. Am J Hum Genet 2004;75:376-385.

6 Hassold T, Sherman S: Down syndrome: genetic recombination and origin of the extra chromosome 21. Clin Genet 2000;57:95-100.

7 Morton NE, Jacobs PA, Hassold T, Wu D: Maternal age in trisomy. Ann Hum Genet 1998;52:227-235.

${ }_{8}$ Lamb NE, Yu K, Shaffer J, Feingold E, Sherman SL: Association between maternal age and meiotic recombination for trisomy 21 . Am J Hum Genet 2005;76:91-99.

-9 Farag TI, Al-Awadi SA, Al-Othman SA, Sundareshan TS, Krishna Murthy DS, Usha R,
Mady SA, Uma R: Down syndrome and tri- $>19$ Mokhtar MM, Abdel-Azziz AM, Nazmy NA, somy 18 in the Bedouins. Am J Med Genet 1988;29:943-944.

10 Al-Naggar RL, Mady SA, Tayel SM, Farag TI, Al-Awadi SA, Al-Ghanim MM, Abulhasan SJ, Sabry MA, Bastaki L: Profile of chromosomal abnormalities in the $\mathrm{Al}$ Jahara region of Kuwait. Med Princ Pract 1999;8:167-172.

11 Verma IC, Mathews AR, Faquih A, El-Zouki AA, Malik GR, Mohammed F: Cytogenetic analysis of Down syndrome in Libya. Indian J Pediatr 1990;57:245-248.

12 Harlap S: Down syndrome in West Jerusalem. Am J Epidemiol 1974;94:225-232.

13 Merrick J: Incidence and mortality of Down syndrome. Isr Med Assoc J 2000;2:25-26.

14 Abeliovich D, Atia Y, Sarov B: Down syndrome in Negev region. Am J Med Genet 1986;25:183.

15 Niazi MA, Al-Mazyad AS, Al-Husain MA, Al-Mofada SM, Al-Zamil FA, Khashoggi TY, Al-Eissa YA: Down syndrome in Saudi Arabia: incidence and cytogenetics. Hum Hered 1995;45:65-69.

16 Amir IM, Al-Tawila KA, Al-Harbi: Cytogenetics and prevalence of Down syndrome: a study from Saudi Arabia. Am J Hum Genet 2002;71(suppl): abstract 1204 .

17 Wahab AA, Bener A, Teebi AS: The incidence patterns of Down syndrome in Qatar. Clin Genet 2006;69:360-362.

18 Zahed L, Megarbane A: A cytogenetic registry of Down syndrome in Lebanon. Commun Genet 1998;1:84-89. Mahrous HS: Cytogenetic profile of Down syndrome in Alexandria, Egypt. East Mediterr Health J 2003;9:37-44.

20 Seabright M: A rapid banding technique for human chromosomes. Lancet 1971;ii:971972.

21 Clementi M, Bianca S, Benedicenti F, Tenconi R, Working Group on Down Syndrome: Down syndrome and parity. Commun Genet 1999;2:18-22.

22 Kallan K: Parity and Down syndrome. Am J Med Genet 1997;70:196-201.

-23 Schimmel MS, Eidelman AI, Hammerman C, Kornbluth E, Zadka P: Increased parity and risk of trisomy 21: Review of 37,110 live births. BMJ 1997;314:720.

24 Chan A, McCaul KA, Keane RJ, Haan EA: Effect of parity, gravidity, previous miscarriage and age on risk of Down syndrome: population study. BMJ 1998;317:923-924.

25 Doria-Rose VP, Kim HS, Augustine ET, Edwards KL: Parity and the risk of Down's syndrome. Am J Epidemiol 2003;158:503508.

26 Krishna Murthy DS, Farag TI: Recurrent regular trisomy-21 in two Bedouin families. Parental mosaicism versus genetic predisposition. Ann Genet 1995;38:217-224.

27 Carothers AD, Hecht CA, Hook EB: International variation in reported liveborth prevalence rates of Down syndrome, adjusted for maternal age. J Med Genet 1999;36:386393. 